\title{
Qual o intervalo de tempo sugerido para a troca de luvas cirúrgicas?
}

\section{Uma revisão integrativa}

Adriana Cristina de Oliveira ${ }^{1}$, Camila Sarmento Gama ${ }^{2}$, Patrícia Reis França ${ }^{3}$

\footnotetext{
${ }^{1}$ Enfermeira, Doutora em Enfermagem. Professora Associada da Universidade Federal de Minas Gerais. Belo Horizonte, MG, Brasil. E-mail: adrianacoliveira@gmail.com.

${ }^{2}$ Enfermeira, Mestre em Enfermagem. Discente do Programa de Pós-Graduação em Enfermagem, nível Doutorado, da Universidade Federal de Minas Gerais. Belo Horizonte, MG, Brasil. E-mail: camilasarmentogama@gmail.com.

${ }^{3}$ Enfermeira. Enfermeira do Hospital Lifecenter. Belo Horizonte, MG, Brasil. Email: patricia.rfranca@hotmail.com.
}

Recebido: 05/08/2015.

Aceito: 29/06/2016.

Publicado: 21/12/2016.

Como citar esse artigo:

Oliveira AC, Gama GS, França PR. Qual o intervalo de tempo sugerido para a troca de luvas cirúrgicas? Uma revisão integrativa. Rev. Eletr. Enf. [Internet]. 2016 [acesso em:______] 18:e1196. Disponível em: http://dx.doi.org/10.5216/ree.v18.37036.

\section{RESUMO}

A troca das luvas cirúrgicas durante o procedimento constitui uma importante medida para a manutenção da sua integridade e prevenção da infecção do sítio cirúrgico, entretanto existe pouco consenso quanto ao tempo para essas trocas. Objetivou-se identificar, analisar e sintetizar os achados disponíveis na literatura sobre o intervalo de tempo sugerido para a troca das luvas cirúrgicas durante as cirurgias com intuito de manter a sua integridade. Tratou-se de uma revisão integrativa de estudos publicados entre 2003 e 2016. Foram selecionados 19 artigos que abordaram a relação integridade da luva cirúrgica e seu tempo de uso. Os estudos apontaram a relação direta entre tempo da cirurgia e aumento do percentual de perfuração das luvas. Com base na análise realizada, sugere-se a troca em menos de 120 minutos para cirurgias do aparelho digestivo, ginecológicas e torácicas. A elaboração de protocolos relativos às diferentes especialidades cirúrgicas deve ser considerada.

Descritores: Luvas Cirúrgicas; Exposição a Agentes Biológicos; Procedimentos Cirúrgicos Operatórios.

\section{INTRODUÇÃO}

A infecção do sítio cirúrgico (ISC) é uma das complicações mais frequentes em pacientes que se submetem a cirurgias, correspondendo a cerca de 160.000-300.000 eventos a cada ano nos Estados Unidos ${ }^{(1)}$ e estão na terceira posição dentre as infecções relacionadas à assistência à saúde (IRAS) no Brasil, compreendendo entre 14 a $16 \%$ das infecções em pacientes hospitalizados ${ }^{(2)}$. Além disso, são as infecções de maior custo e passíveis de prevenção em até $60 \%$ dos $\operatorname{casos}^{(1)}$.

A fim de prevenir o desenvolvimento das ISC boas práticas devem ser adotadas pela equipe cirúrgica 
como a utilização de luvas estéreis durante os procedimentos operatórios.

As luvas cirúrgicas estéreis são usadas de forma complementar à antissepsia cirúrgica das mãos e proporcionam barreira física para os micro-organismos presentes nas mãos dos profissionais de saúde, nos equipamentos e nos pacientes ${ }^{(3-4)}$.

Entretanto, sua utilização é passível de falhas, sendo comum a ocorrência de (micro) perfurações/rasgos que comprometem a capacidade de proteção dos pacientes ${ }^{(5)}$. A exposição a materiais perfurocortantes, fragmentos ósseos e produtos químicos favorecem a ruptura de sua integridade ${ }^{(6)}$ que, muitas vezes, sequer são percebidas pelos profissionais ${ }^{(7)}$.

A integridade das luvas está diretamente associada ao tipo e qualidade do seu material, à intensidade e duração de seu uso, à realização de testes prévios e posteriores a sua utilização e ao método utilizado para a deteç̧ão de vazamentos bem como da habilidade do cirurgião em seu uso ${ }^{(4)}$.

Estima-se que ocorram em média 18\% (IC 5-82\%) de (micro) perfurações/rasgos nas luvas durante a execução dos procedimentos ${ }^{(3,5)}$ que viabilizam a transferência de micro-organismos ${ }^{(7)}$, podendo este evento dobrar o risco de $\mathrm{ISC}^{(8)}$.

Neste contexto, evidencia-se que a perfuração das luvas cirúrgicas contribui como uma fonte importante de transferência de micro-organismos para a ferida cirúrgica ${ }^{(7,9)}$. Assim, a fim de minimizar os danos decorrentes da presença de micro-organismos na ferida operatória provenientes das mãos dos profissionais da equipe cirúrgica, recomenda-se: a troca de luvas em intervalos regulares ou a qualquer momento em caso de detecção de perfuração ${ }^{(10)}$; e o enluvamento duplo diante de procedimentos cirúrgicos que envolvam uso de próteses ${ }^{(4,10)}$ em procedimentos prolongados, em situações com elevado risco de perfurações $^{(11)}$ ou quando a exposição a fluidos corporais é alta ${ }^{(4)}$.

Apesar da forte associação entre o tempo de uso das luvas cirúrgicas e a ocorrência de perfuração evidenciada em muitos estudos, capaz de influenciar na ocorrência da $\operatorname{ISC}^{(7,12-15)}$, a ênfase na troca das luvas durante o ato operatório nem sempre tem sido destacada ou quando é mencionada há pouco consenso quanto ao intervalo de tempo preconizado tendo em vista os diferentes procedimentos existentes.

Diante do exposto, esse estudo busca responder à seguinte questão: qual o intervalo de tempo sugerido para a troca de luvas cirúrgicas visando à manutenção da sua integridade? A explanação desse questionamento visa subsidiar os profissionais de saúde das equipes cirúrgicas na implantação de uma prática mais segura à medida que poderá contribuir para a elaboração de protocolos com intervalos de tempo para a troca de luvas estéreis durante o procedimento cirúrgico, de forma a manter a integridade das luvas e, consequentemente, reduzir o potencial de transferência de micro-organismos da pele do profissional para a ferida cirúrgica.

Assim, objetivou-se identificar, analisar e sintetizar os achados disponíveis na literatura sobre o intervalo de tempo sugerido para a troca das luvas cirúrgicas durante as cirurgias com intuito de manter a integridade das mesmas durante todo o procedimento. 


\section{MÉTODOS}

Trata-se de uma revisão integrativa, que tem como característica o estudo de pesquisas desenvolvidas com o intuito de aperfeiçoar o conhecimento científico e as práticas profissionais ${ }^{(16)}$, realizada seguindo as seguintes etapas: identificação da questão de pesquisa e seu objetivo, busca na literatura, formação de banco de dados, análise dos estudos encontrados, interpretação dos dados e discussão dos resultados.

Para realização do estudo, levou-se em consideração a necessidade de identificação de um tempo sugerido para realização da troca de luvas cirúrgicas durante procedimentos operatórios, visando à redução das taxas de perfuração de luvas e, consequentemente, da transmissão de micro-organismos potenciais causadores de infecções entre pacientes.

A busca foi realizada em periódicos publicados em inglês, espanhol e português por meio do Portal da Coordenação de Aperfeiçoamento de Pessoal de Nível Superior, cujas bases de dados foram ScienceDirect, Scopus e Web of Science.

Realizou-se a busca de estudos publicados no período de 2003 a 2016 utilizando os descritores DECS/MESH "luvas cirúrgicas (surgical, gloves/guantes quirúrgicos)", "exposição a agentes biológicos (exposure to biological agentes/exposición a agente biológico)", "procedimentos cirúrgicos operatórios (surgical procedures, operative/procedimentos quirúrgicos operativos)" e o termo "perfuração de luva (glove perforation/perforación de guantes)" que inexiste nos descritores DECS/MESH, mas foi inserido devido a maior precisão de busca dos artigos relacionados à temática.

Foram estabelecidos como critérios de inclusão artigos originais que se referiam a relação entre integridade da luva cirúrgica e tempo de uso. E foram excluídos aqueles que abordaram somente taxa de perfuração sem relacioná-la ao tempo de uso, os estudos que seguiram um protocolo de troca predeterminado e que não estavam disponíveis na íntegra.

Após a leitura dos títulos, 94 artigos foram pré-selecionados: 45 publicados na Scopus, 12 na Science Direct e 37 na Web of Science. Foram excluídos por duplicação em bases diferentes e indisponibilidade integral 46, restando 48. Desse total, após a leitura dos resumos, foram selecionados 26 que foram lidos na íntegra.

Realizou-se um fichamento dessas publicações com as seguintes informações: título, autor, ano de publicação, especialidade cirúrgica, tipo de cirurgia, função desempenhada na equipe cirúrgica, número de luvas avaliadas, material das luvas, tipo de enluvamento e percentual de perfuração por tempo de uso, sete $(26,9 \%)$ foram excluídos, pois não continham dados de perfuração das luvas por tempo de uso de forma clara ou determinavam um protocolo para a troca das luvas em determinados intervalos de tempo, dificultando a análise do comportamento das luvas em períodos prolongados. A análise final foi composta por 19 artigos.

Posteriormente à análise dessa síntese, as especialidades cirúrgicas descritas em mais de um artigo foram agrupadas, por se tratarem da mesma área, e o intervalo de tempo sugerido para a troca das luvas foi determinado por especialidade com base na junção de intervalos similares entre esses artigos e no cálculo da média de perfuração por intervalo. As especialidades que só continham um artigo publicado, esse foi 
considerado como referência para a sugestão do tempo de troca, sendo avaliado o intervalo com maior percentual de perfuração e a recomendação feita antes desse tempo "crítico".

\section{RESULTADOS}

Os 19 artigos selecionados foram de procedimentos e especialidades distintos, com diferentes metodologias. Os estudos obtiveram os percentuais de perfurações/rasgos registrados de acordo com seus respectivos tempos de cirurgia e tempo de uso da luva. Para fins de análise considerou-se equivalente o tempo de cirurgia e o tempo de uso da luva uma vez que, geralmente, o calçamento da luva se faz imediatamente antes do início do procedimento e a sua retirada é feita logo após o fechamento da incisão, isto é, ao término da cirurgia (Quadro 1). 
Quadro 1: Caracterização da perfuração das luvas cirúrgicas por tempo de cirurgia em diversos procedimentos.

\begin{tabular}{|c|c|c|c|c|c|c|}
\hline $\begin{array}{c}\text { Autores/país de } \\
\text { origem/ano/tipo de } \\
\text { estudo }\end{array}$ & Tipo de Cirurgia & Especialidade & $\begin{array}{l}\text { № de Luvas } \\
\text { Avaliadas }\end{array}$ & Teste de perfuração & $\begin{array}{l}\text { Tipo de } \\
\text { Enluvamento }\end{array}$ & $\begin{array}{l}\text { Percentual de Perfuração por } \\
\text { Tempo de Uso da luva }\end{array}$ \\
\hline $\begin{array}{l}\text { Harnoß et al. }^{(7)} \\
\text { Alemanha } \\
2010 \\
\text { Prospectivo }\end{array}$ & $\begin{array}{c}\text { Perfurações e ressecções do trato } \\
\text { gastrointestinal, lavagens abdominais e } \\
\text { laparotomias exploratórias }\end{array}$ & Aparelho digestivo & $\begin{array}{l}250 \text { luvas } \\
128 \text { luvas } \\
\text { externas } \\
122 \text { luvas } \\
\text { internas }\end{array}$ & Teste de água & $\begin{array}{l}\text { Único } \\
\text { Duplo }\end{array}$ & $\begin{array}{c}<90 \min : 4 / 86-4,7 \% \\
91 \text { a } 150 \min : 20 / 84-23,8 \% \\
>151 \min : 21 / 80-26,3 \%\end{array}$ \\
\hline $\begin{array}{l}\text { Partecke et al. } \\
\text { Alemanha } \\
2009 \\
\text { Prospectivo }\end{array}$ & $\begin{array}{c}\text { Cirurgia geral: } \\
\text { Procedimentos laparoscópicos (cirurgias de } \\
\text { ductos biliares, apendicectomias, reparos de } \\
\text { hérnias), cirurgias abdominais pequenas, } \\
\text { médias e grandes, procedimentos vasculares e } \\
\text { cardiotorácicos }\end{array}$ & $\begin{array}{l}\text { Aparelho digestivo e } \\
\text { Cardiovasculares }\end{array}$ & $\begin{array}{l}898 \text { pares de } \\
\text { luvas }\end{array}$ & Teste de água & Não menciona & $\begin{array}{l}\leq 90 \text { minutos: } 46(15,4 \%) \\
91-150 \text { minutos: } 54(18,1 \%) \\
>150 \text { minutos: } 71(23,7 \%)\end{array}$ \\
\hline $\begin{array}{l}{\text { Oliveira } \& \text { Gama }^{(15)}}^{\text {Brasil }} \\
2014 \\
\text { Estudo Transversal }\end{array}$ & $\begin{array}{c}\text { Procedimentos indefinidos: } \\
\text { Cirurgias do aparelho digestivo } \\
\text { Cardiovascular } \\
\text { Pediatria }\end{array}$ & $\begin{array}{l}\text { Aparelho digestivo } \\
\text { Cardiovascular } \\
\text { Pediatria }\end{array}$ & $\begin{array}{c}1090 \\
148 \text { duplos } \\
942 \text { únicos } \\
\end{array}$ & Teste de água & $\begin{array}{l}\text { Único } \\
\text { Duplo }\end{array}$ & $\begin{array}{c}\leq 29 \text { minutos: } 13(9,9 \%) \\
30-119 \text { minutos: } 55(42 \%) \\
\geq 120 \text { minutos: } 63(48,1 \%)\end{array}$ \\
\hline $\begin{array}{l}\text { Manjunath et al. }{ }^{(17)} \\
\text { Inglaterra } \\
2008 \\
\text { Prospectivo }\end{array}$ & Laparotomia & $\begin{array}{l}\text { Ginecologia e } \\
\text { obstetrícia }\end{array}$ & $\begin{array}{l}462 \text { luvas } \\
154 \text { único } \\
18 \text { duplo } \\
290 \text { duplo } \\
\text { com indicador }\end{array}$ & $\begin{array}{l}\text { Teste com insuflação de ar } \\
\text { e imersão na água para } \\
\text { detecção de bolhas. }\end{array}$ & $\begin{array}{l}\text { Único } \\
\text { Duplo } \\
\text { Duplo com } \\
\text { indicador }\end{array}$ & $\begin{array}{l}\leq 180 \min : 25(1,6 \%) \\
180-300 \mathrm{~min}: 17(1,9 \%) \\
\geq 300 \mathrm{~min}: 19(4,8 \%)\end{array}$ \\
\hline $\begin{array}{c}\text { Yinusa et al. }{ }^{(18)} \\
\text { China } \\
2003 \\
\text { Prospectivo }\end{array}$ & Pediatria, coluna e mãos & Ortopedia pediátrica & 792 luvas & Teste de água & $\begin{array}{l}\text { Único } \\
\text { Duplo }\end{array}$ & $\begin{array}{c}30-60 \min : 8(30,8 \%) \\
61-120 \min : 12(36,4 \%) \\
121-180 \min : 9(47,4 \%) \\
>180 \min : 16(72,7 \%)\end{array}$ \\
\hline $\begin{array}{c}\text { Malhotra et al. }^{(19)} \\
\text { India } \\
2004 \\
\text { Prospectivo }\end{array}$ & $\begin{array}{l}\text { Cesáreas, histerectomias e laparotomias } \\
\text { exploratórias }\end{array}$ & $\begin{array}{l}\text { Ginecologia e } \\
\text { obstetrícia }\end{array}$ & $\begin{array}{l}1120 \text { luvas } \\
592 \text { internas } \\
528 \text { externas }\end{array}$ & Teste de água & $\begin{array}{l}\text { Único } \\
\text { Duplo }\end{array}$ & $\begin{array}{l}<40 \min : 40(7,6 \%) \\
>40 \min : 112(18,6 \%)\end{array}$ \\
\hline
\end{tabular}




\begin{tabular}{|c|c|c|c|c|c|c|}
\hline $\begin{array}{c}\text { Autores/país de } \\
\text { origem/ano/tipo de } \\
\text { estudo }\end{array}$ & Tipo de Cirurgia & Especialidade & $\begin{array}{l}\text { № de Luvas } \\
\text { Avaliadas }\end{array}$ & Teste de perfuração & $\begin{array}{c}\text { Tipo de } \\
\text { Enluvamento }\end{array}$ & $\begin{array}{l}\text { Percentual de Perfuração por } \\
\text { Tempo de Uso da luva }\end{array}$ \\
\hline $\begin{array}{c}\text { Al-Habdan \& Sadat- } \\
\text { Ali }^{(20)} \\
\text { Arábia Saudita } \\
2003 \\
\text { Prospectivo }\end{array}$ & Osteotomias pélvica e femoral & Ortopedia pediátrica & 427 pares & Teste de água & $\begin{array}{c}\text { Não } \\
\text { mencionado }\end{array}$ & > 120 minutos: 57 (79\%) \\
\hline $\begin{array}{c}\text { Oliveira \& Gama }^{(21)} \\
\text { Brasil } \\
2015 \\
\text { Transversal }\end{array}$ & $\begin{array}{c}\text { Procedimentos indefinidos: } \\
\text { Cirurgias do aparelho digestivo } \\
\text { Cardiovascular } \\
\text { Pediatria }\end{array}$ & $\begin{array}{l}\text { Aparelho digestivo } \\
\text { Cardiovascular } \\
\text { Pediatria }\end{array}$ & 214 & Teste de água & $\begin{array}{l}\text { Único } \\
\text { Duplo }\end{array}$ & $\begin{array}{l}\leq 29 \text { minutos: } 7(30,4 \%) \\
30-119 \text { minutos: } 6(26,1 \%) \\
\geq 120 \text { minutos: } 10(43,5 \%)\end{array}$ \\
\hline $\begin{array}{l}\text { Al-Habdan, Corea \& } \\
\text { Sadat-Ali } \\
\text { Arábia Saudita } \\
2006 \\
\text { Prospectivo }\end{array}$ & Cirurgias ortopédicas pediátricas & Ortopedia pediátrica & $\begin{array}{l}526 \text { duplos } \\
316 \\
\text { únic } \\
\text { os }\end{array}$ & Teste de água & $\begin{array}{l}\text { Único } \\
\text { Duplo }\end{array}$ & $\begin{array}{l}\text { < } 60 \text { minutos: enluvamento } \\
\text { duplo não houve perfuração; } \\
\text { único } 3 \text { luvas perfuradas } \\
\text { 60-120 minutos: enluvamento } \\
\text { duplo } 11 \text { luvas perfuradas; } \\
\text { único } 21 \text { luvas perfuradas } \\
>120 \text { minutos: enluvamento } \\
\text { duplo } 32 \text { luvas perfuradas; } \\
\text { único } 4 \text { luvas perfuradas }\end{array}$ \\
\hline $\begin{array}{c}\text { Murta, Silva \& } \\
\text { Júnior }^{(23)} \\
\text { Brasil } \\
2003 \\
\text { Prospectivo }\end{array}$ & $\begin{array}{c}\text { Cirurgias } \\
\text { ginecológicas e obstétricas }\end{array}$ & $\begin{array}{c}\text { Ginecologia e } \\
\text { obstetrícia }\end{array}$ & $\begin{array}{l}792 \text { duplos } \\
240 \text { únicos }\end{array}$ & Teste de água & $\begin{array}{l}\text { Único } \\
\text { Duplo }\end{array}$ & $\begin{array}{c}\text { < } 120 \text { minutos: enluvamento } \\
\text { duplo } 3(30 \%) \text { luvas } \\
\text { perfuradas; único } 2(20 \%) \text { luvas } \\
\text { perfuradas } \\
>120 \text { minutos: enluvamento } \\
\text { duplo } 24(58,5 \%) \text { luvas } \\
\text { perfuradas; único } 14(56 \%) \\
\text { luvas perfuradas }\end{array}$ \\
\hline $\begin{array}{l}\text { Laine et al. }^{(24)} \\
\text { Finlândia } \\
2004 \\
\text { Prospectivo } \\
\text { randomizado }\end{array}$ & $\begin{array}{l}\text { Cirurgias gastrintestinais: apendicectomias, } \\
\text { hemicolectomias, cirurgias de câncer, } \\
\text { colecistectomias }\end{array}$ & Aparelho digestivo & 814 luvas & Teste de água & $\begin{array}{l}\text { Único } \\
\text { Duplo }\end{array}$ & $\begin{array}{l}<120 \text { minutos: } 26(8,2 \%) \\
>120 \text { minutos: } 41(10,9 \%)\end{array}$ \\
\hline
\end{tabular}




\begin{tabular}{|c|c|c|c|c|c|c|}
\hline $\begin{array}{c}\text { Autores/país de } \\
\text { origem/ano/tipo de } \\
\text { estudo }\end{array}$ & Tipo de Cirurgia & Especialidade & $\begin{array}{l}\text { № de Luvas } \\
\text { Avaliadas }\end{array}$ & Teste de perfuração & $\begin{array}{c}\text { Tipo de } \\
\text { Enluvamento }\end{array}$ & $\begin{array}{l}\text { Percentual de Perfuração por } \\
\text { Tempo de Uso da luva }\end{array}$ \\
\hline $\begin{array}{c}\text { Dhar }^{(25)} \\
\text { Omã } \\
2011 \\
\text { Prospectivo }\end{array}$ & Cirurgias ortopédicas & Ortopedia & $\begin{array}{l}404 \text { luvas } \\
369 \text { duplos } \\
35 \text { únicos }\end{array}$ & Teste de água & $\begin{array}{l}\text { Único } \\
\text { Duplo }\end{array}$ & $\begin{array}{c}\text { 30-60 minutos: } 16(26,2 \%) \\
\text { 60-90 minutos: } 11(18 \%) \\
\text { 90-120 minutos: } 16(26,2 \%) \\
\text { >120 minutos: } 18(29,6 \%)\end{array}$ \\
\hline $\begin{array}{l}\text { Shek \& } \text { Chau }^{(26)} \\
\text { China } \\
2013 \\
\text { Caso controle }\end{array}$ & Cirurgias oftálmicas & Oftalmologia & 100 luvas & Teste de água & Único & $\begin{array}{l}<60 \text { minutos: } 4(4 \%) \\
>60 \text { minutos: } 0(0 \%)\end{array}$ \\
\hline $\begin{array}{l}\text { Kuroyanagi et al. }^{(27)} \\
\text { Japão } \\
2012 \\
\text { Prospectivo }\end{array}$ & Cirurgia oral e maxilofacial & Oral e maxilofacial & 1436 luvas & Teste de água & $\begin{array}{l}\text { Único } \\
\text { Duplo }\end{array}$ & $\begin{array}{c}95,3 \text { minutos } \pm 55,7 \text { minutos: } \\
82(54,7 \%)\end{array}$ \\
\hline $\begin{array}{c}\text { Castro-Peraza et } \\
\text { al. }{ }^{(28)} \\
\text { Ilhas Canárias } \\
2010 \\
\text { Ensaio clínico } \\
\text { controlado e } \\
\text { randomizado }\end{array}$ & $\begin{array}{l}\text { Diversos procedimentos: } \\
\text { Cirurgias de grande porte, pequeno porte e } \\
\text { videolaparoscópicas }\end{array}$ & Não mencionado & $\begin{array}{l}1537 \\
\text { luvas }\end{array}$ & Teste de água & $\begin{array}{l}\text { Único } \\
\text { Duplo }\end{array}$ & $\begin{array}{l}\text { Cirurgia grande porte - Média } \\
\text { de duração } 85,16 \text { minutos: } 86 \\
(7,88 \%) \text { perfurações } \\
\text { Cirurgia pequeno porte - Média } \\
\text { de duração } 53,75 \text { minutos: } 5 \\
(2,35 \%) \text { perfurações } \\
\text { Cirurgia videolaparoscópica - } \\
\text { Média de duração } 90,13 \\
\text { minutos: } 13(5,60 \%) \\
\text { perfurações }\end{array}$ \\
\hline $\begin{array}{l}\text { Kojima \& Ohashi }^{(29)} \\
\text { Japão } \\
2005 \\
\text { Prospectivo }\end{array}$ & Toracoscopia toracotomia aberta & Tórax & 117 luvas & Teste de água & $\begin{array}{l}\text { Não } \\
\text { mencionado }\end{array}$ & $\begin{array}{l}<120 \min : 11(16,9 \%) \\
>120 \min : 22(42,3 \%)\end{array}$ \\
\hline $\begin{array}{c}\text { Guo et al. }{ }^{(30)} \\
\text { China } \\
2012 \\
\text { Prospectivo } \\
\text { randomizado }\end{array}$ & $\begin{array}{l}\text { Cesárea, colecistectomia, gastrectomia, } \\
\text { reparação de hérnia, histerectomia, } \\
\text { laparotomia e nefrectomia }\end{array}$ & $\begin{array}{l}\text { Ginecologia } \\
\text { Aparelho digestivo } \\
\text { Urologia }\end{array}$ & $\begin{array}{l}218 \text { luvas } \\
112 \text { simples } \\
106 \text { duplo }\end{array}$ & $\begin{array}{l}\text { Teste com insuflação de ar } \\
\text { e imersão na água para } \\
\text { detecção de bolhas. } \\
\text { Validação posterior com o } \\
\text { teste de água }\end{array}$ & $\begin{array}{l}\text { Único } \\
\text { Duplo }\end{array}$ & $\begin{array}{l}\text { A média de duração do uso das } \\
\text { luvas perfuradas foi de } 69,8 \\
\text { minutos: } 10,09 \% \text { perfurações }\end{array}$ \\
\hline
\end{tabular}




\begin{tabular}{|c|c|c|c|c|c|c|}
\hline $\begin{array}{c}\text { Autores/país de } \\
\text { origem/ano/tipo de } \\
\text { estudo }\end{array}$ & Tipo de Cirurgia & Especialidade & $\begin{array}{l}\text { № de Luvas } \\
\text { Avaliadas }\end{array}$ & Teste de perfuração & $\begin{array}{c}\text { Tipo de } \\
\text { Enluvamento }\end{array}$ & $\begin{array}{l}\text { Percentual de Perfuração por } \\
\text { Tempo de Uso da luva }\end{array}$ \\
\hline $\begin{array}{l}\text { Hübner et al. } \\
2010 \\
\text { Prospectivo }\end{array}$ & Laparotomias & Aparelho digestivo & 194 luvas & Teste de água & Duplo & $\begin{array}{l}\text { Média de tempo de uso da } \\
\text { luva: } 99,6 \text { minutos - } 10(10,2 \%) \\
\text { luvas externas e } 1(1,04 \%) \\
\text { internas }\end{array}$ \\
\hline $\begin{array}{l}\text { Korniewicz et al. } \\
2004 \\
\text { Ensaio clínico }\end{array}$ & 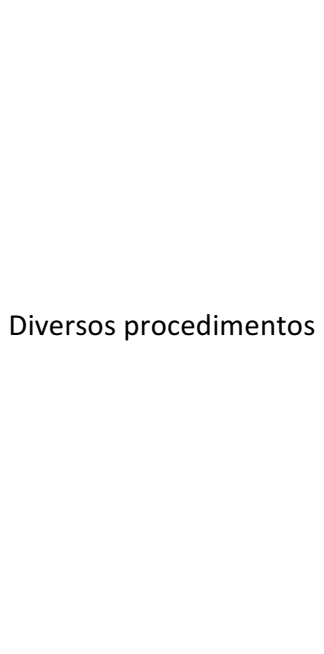 & $\begin{array}{c}\text { Oral } \\
\text { Plástica } \\
\text { Dental } \\
\text { Cardiovascular } \\
\text { Ortopedia } \\
\text { Urologia } \\
\text { Neurologia } \\
\text { Ginecologia e } \\
\text { obstetrícia } \\
\text { Otorrinolaringologia } \\
\text { Tórax } \\
\text { Transplante } \\
\text { Geral } \\
\text { Pediatria } \\
\text { Oftalmologia }\end{array}$ & 6386 & Teste de água & Não menciona & $\begin{array}{c}<60 \text { minutos: taxa de } 0,03 \\
\text { perfurações detectadas nas } \\
\text { luvas de látex } \\
120 \text { minutos: taxa de } \cong 0,043 \\
\text { perfurações } \\
180 \text { minutos: } \cong 0,045 \\
\text { perfurações } \\
300 \text { minutos: } \cong 0,057 \\
\text { perfurações } \\
480 \text { minutos: } \cong 0,09 \\
660 \text { minutos: } \cong 0,125 \\
\text { perfurações }\end{array}$ \\
\hline
\end{tabular}


Desse total, nove trabalharam com a luva de látex ${ }^{(15,18-19,21-22,24,27,29-30)}$, um $^{(32)}$ comparou a luva de látex com as de não-látex e nove mencionaram a marca registrada utilizada, mas não o material ${ }^{(7,12,17,20,23,25-26,28,31)}$.

Todos os estudos realizaram o teste das luvas após o seu uso no final da cirurgia, sendo que a maioria utilizou o teste que consiste no preenchimento da luva com água e pressão sob os dedos e palmas para deteç̧ão de vazamento ${ }^{(7,12,18-29,31-32)}$, conforme descrito pela Norma Europeia EN 455-1 ${ }^{(33)}$. Um estudo realizou o teste de insuflação da luva com ar e imersão na água para detecção de bolhas ${ }^{(17)}$ e outro usou ambos os testes a título de validação ${ }^{(30)}$.

As equipes cirúrgicas participantes eram compostas por cirurgião, assistentes e enfermeiros que utilizaram luvas de látex estéreis. Em geral, dentre estas equipes, os cirurgiões foram os profissionais que apresentaram os maiores índices de perfurações, sendo os dedos polegar e indicador da mão não dominante os representantes dos principais sítios de perfuração ${ }^{(7,15,17,21-23,25,31)}$.

Diante de dados tão heterogêneos, como os procedimentos abordados, especialidades, duração da cirurgia, tempo médio de uso da luva, observou-se a necessidade de reunir intervalos similares desses artigos calculando uma média de perfuração de cada intervalo quando da existência de mais de um artigo da mesma especialidade. Essas médias foram plotadas em um gráfico: perfuração $X$ tempo de cirurgia, tornando possível analisar o comportamento da perfuração, visando a busca de um tempo ótimo de troca.

\section{Ginecologia e Obstetrícia}

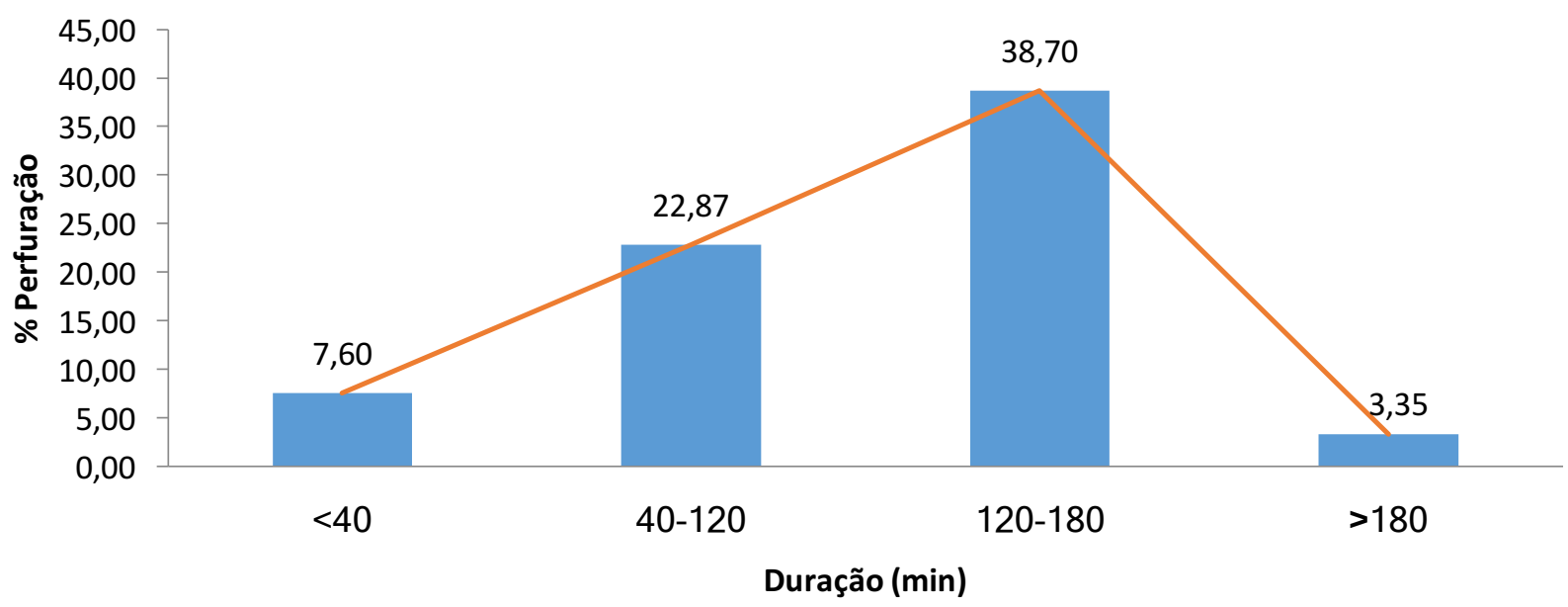

Figura 1: Estimativa do intervalo de tempo sugerido de trocas das luvas cirúrgicas na ginecologia e obstetrícia. $\mathrm{N}=3^{(17,19,23)}$. 


\section{Ortopedia Pediátrica}

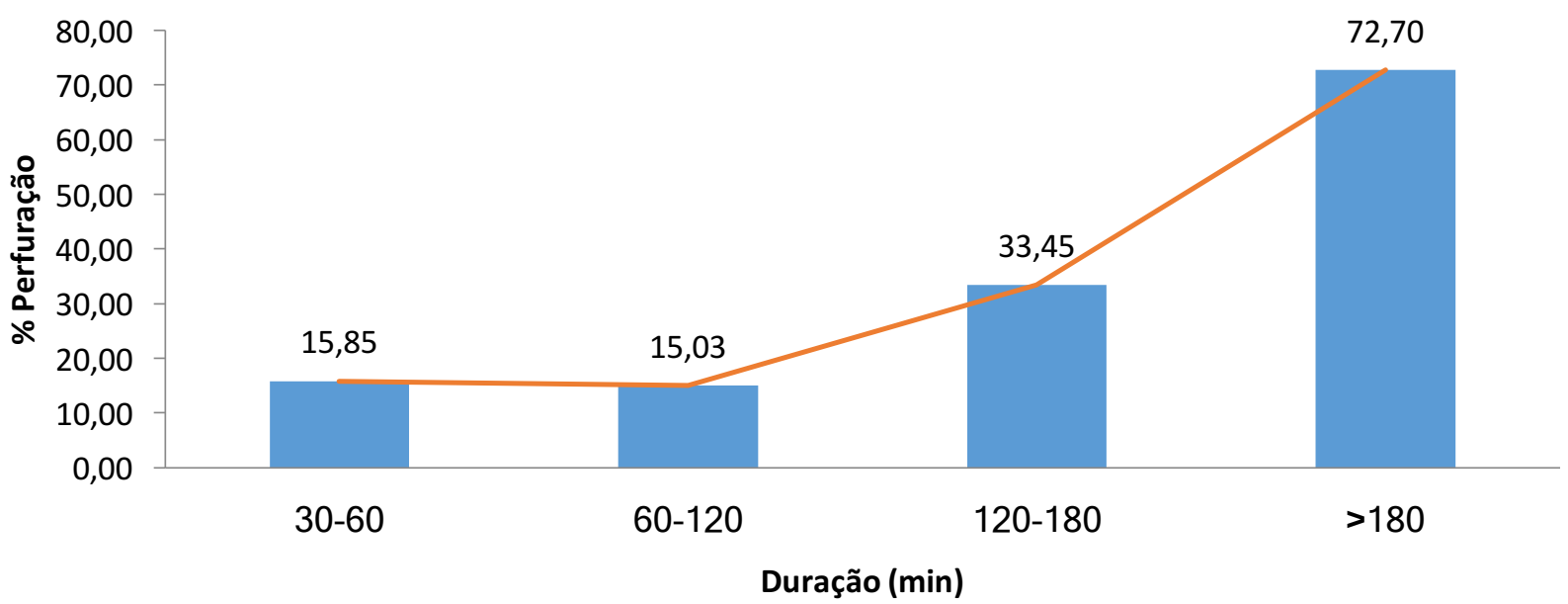

Figura 2: Estimativa do intervalo de tempo sugerido de trocas das luvas cirúrgicas na ortopedia pediátrica. $\mathrm{N}=3^{(18,20,22)}$.

\section{Aparelho Digestivo}

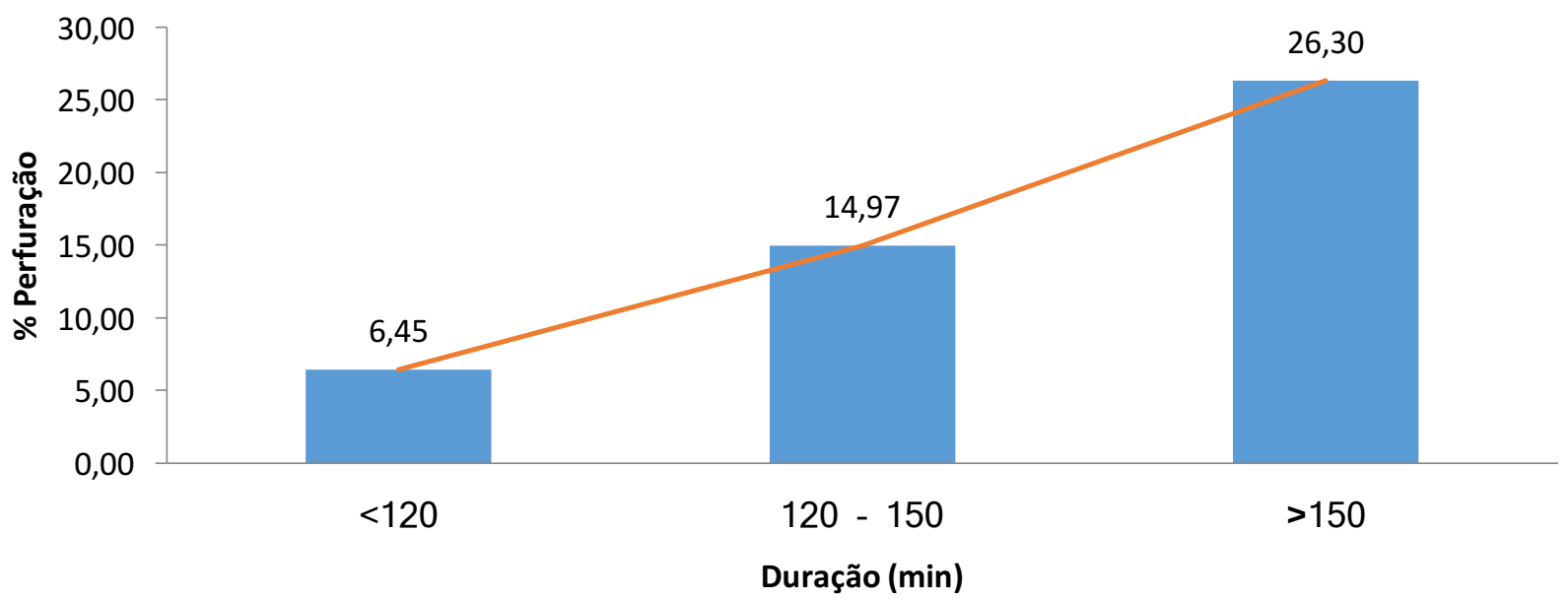

Figura 3: Estimativa do intervalo de tempo sugerido de trocas das luvas cirúrgicas em cirurgias do aparelho digestivo. $N=3^{(7,24,31)}$.

Diante dos gráficos elaborados e do quadro apresentados, sugere-se que a troca das luvas em cirurgias ginecológicas e obstétricas, ortopédicas pediátricas e do aparelho digestivo ocorra antes de 120 minutos, que foi o intervalo de tempo em que houve um aumento considerável do percentual de perfurações.

Para as especialidades que tiveram somente um estudo relacionado, considerou-se o intervalo com maior percentual de perfuração, recomendando-se a troca antes desse tempo "crítico". Assim, nas cirurgias torácicas a troca deve preceder os 120 minutos; nas cirurgias orais e maxilofaciais os 90 minutos; e nas oftálmicas os 60 minutos.

Nos estudos em que houve uma diversidade de especialidades avaliadas ${ }^{(12,15,28,30,32)}$ pode se observar que o aumento do tempo esteve relacionado com maiores taxas de perfuração das luvas. No entanto, não foi possível determinar um tempo de troca ideal para as mesmas, uma vez que cada especialidade possui sua especificidade como quanto ao material perfurocortante usado, a complexidade e a duração dos 
procedimentos realizados.

\section{DISCUSSÃO}

\section{Aspectos gerais sobre o tema}

Devido à relevância das luvas cirúrgicas como medida de prevenção da ISC, a sua utilização deve atender a requisitos de segurança para o usuário e para o paciente a ser assistido, respeitando os critérios que padronizem a sua qualidade e efetividade, sendo necessário o cumprimento de normas nacionais e internacionais que regulamentam a sua comercialização e garantam a utilização segura e efetiva.

O órgão americano American Society for Testing and Materials (ASTM) é o responsável pela padronização dos testes de recomendação e regulamentação da comercialização desses produtos nos Estados Unidos. Dessa forma, ele exige dos fabricantes, tanto para luvas de látex quanto para as sintéticas destinadas a procedimentos cirúrgicos, que as mesmas devam ser fabricadas com compostos polímeros de borracha, com as superfícies internas e externas livres de talco. Além disso, preconiza que os ensaios de esterilidade, ausência de orifícios, dimensões e propriedades físicas, resistência à tração, estresse, alongamento final, teor proteico, ausência de resíduos, quantidade de pó e teor de proteína antigênica estejam de acordo com os requisitos padronizados por eles ${ }^{(6,34)}$.

Alguns desses padrões descritos pela ASTM são precisamente determinados como a ausência de microperfuração/orifícios, enquanto outros aceitam variações dentro de um limite pré-determinado, como a dimensão física e a espessura, justificando as diversidades de luvas encontradas no mercado dependendo do fabricante ${ }^{(6)}$.

No Brasil, a Resolução da Diretoria Colegiada 55, publicada em 04 de novembro de 2011, baseada no padrão ISO (International Organization for Standardization) 10282:2005, 11193-2:2006, e 37:2008, exige que as luvas não imponham riscos aos usuários ou pacientes, devendo ser submetidas a processos que garantam a redução do conteúdo proteico, atendendo aos requisitos de ensaios de dimensões físicas, mecânicas, impermeabilidade e microbiológicos ${ }^{(35)}$.

Embora a tecnologia para a produção das luvas cirúrgicas esteja cada vez mais avançada, a detecção de perfurações ainda é inevitável ${ }^{(5,36-37)}$, podendo essas perfurações estarem presentes antes ou após a sua utilização pelo profissional $^{(38)}$.

Apesar da maioria dos estudos trabalhar com a detecção da perfuração após o seu uso, há evidências de passagem de micro-organismos em $65 \%$ das luvas cirúrgicas e $40 \%$ das luvas de procedimento antes da sua utilização, demonstrando perfurações pré-existentes que podem acarretar em riscos para os profissionais e pacientes ${ }^{(38)}$.

\section{Caracterização das perfurações em luvas cirúrgicas}

A maior duração do procedimento cirúrgico está relacionada com o aumento das taxas de perfurações 
nas luvas $s^{(6-7,12,29,32)}$. E a redução da taxa de contaminação microbiana está associada ao aumento da frequência de troca das luvas cirúrgicas ${ }^{(39-40)}$, sendo, portanto, essa prática recomendada durante as cirurgias prolongadas $^{(10)}$. Nesse sentido, alguns estudos que usaram protocolos de troca em determinado tempo, obtiveram queda significativa da taxa de perfuração ${ }^{(41-42)}$.

De acordo com os achados do presente estudo, os tempos de recomendação de troca variaram de menos de 60 minutos a menos de 120 minutos, dependendo da especialidade. A diversidade de especialidades em um mesmo estudo dificultou a análise e inviabilizou a recomendação de um intervalo de tempo para a troca, pois os procedimentos, o tempo de cirurgia e uso da luva foram muito heterogêneos, ratificando a importância da avaliação do tempo de troca da luva por especialidade, procedimento e até mesmo o papel desempenhado durante a cirurgia pelo profissional.

Estudo de revisão semelhante ${ }^{(43)}$ em que as recomendações de tempo de troca de luvas foram avaliadas, a grande variabilidade de dados dificultou uma padronização e convergência para um resultado único. Apenas uma das especialidades avaliadas conseguiu apresentar uma correlação entre tempo de uso da luva com taxa de perfuração.

De acordo com dados da literatura, a ortopedia é a especialidade que deve estar alerta para a troca das luvas cirúrgicas em um menor intervalo de tempo, o que pode ser explicado pelo fato desta especialidade envolver em seus procedimentos uma variedade de materiais perfurocortantes, além de fragmentos ósseos e produtos químicos que atuam como estressores à integridade da luva ${ }^{(6)}$. No presente estudo, somente as ortopedias pediátricas foram avaliadas e o tempo de troca sugerido após a análise dos dados não foi tão curto se comparado a outras especialidades avaliadas.

Nas cirurgias ginecológicas analisadas, observou-se uma queda no número de perfurações em cirurgias maiores do que 180 minutos. Pode-se supor que esse fato seja explicado pelo menor quantitativo de cirurgias com essa duração analisadas e, consequentemente, menor número de luvas avaliados após esse período.

Além da qualidade do material da luva, do tempo de duração, especialidade cirúrgica e instrumentais envolvidos, outros fatores contribuem para a ocorrência de perfurações, como o papel desempenhado pelo profissional da equipe cirúrgica durante o procedimento e sua habilidade técnica ${ }^{(6)}$.

Quanto ao papel desempenhado durante o ato operatório e a relação com a perfuração das luvas, estudos têm demonstrado maior quantitativo de perfurações das luvas entre cirurgiões ${ }^{(15,44)}$, mais frequentemente na mão não dominante, no dedo indicador, seguido do polegar ${ }^{(6-7,12,15)}$. Essa caracterização das perfurações se deve ao fato do cirurgião manipular os instrumentos perfurocortantes com a mão dominante favorecendo a ocorrência dos acidentes na mão oposta ${ }^{(6,12)}$. Nesse sentido, observou-se a necessidade de mais estudos que trabalhem com a recomendação de intervalo de troca por função desempenhada na cirurgia, pois com base nesse pressuposto o tempo de troca do cirurgião tende a ser mais breve do que o tempo de troca do instrumentador, por exemplo.

O tempo de atuação/experiência profissional constitui uma variável importante como fator de risco para a ocorrência de acidentes. A menor habilidade e destreza dos profissionais na execução de 
procedimentos complexos com maior duração e na manipulação do instrumental cirúrgico, podem contribuir fortemente para a maior perfuração das luvas ${ }^{(6,15)}$.

Um dos trabalhos ${ }^{(7)}$ avaliou, além dos índices de perfuração em relação ao tempo de uso, a passagem de micro-organismos através dessas falhas. Esta pesquisa realizou testes in vitro e sob condições clinicas após os procedimentos de laparotomias. A última consistiu na utilização de enluvamento duplo pela equipe cirúrgica sendo o par interno calçado considerado íntegro e o externo com perfurações prévias feitas por agulhas de 22G. As luvas internas foram avaliadas após a remoção das externas utilizando o procedimento modificado de Gaschen.

Encontrou-se a passagem de micro-organismos pela perfuração em 4,7\% das luvas externas examinadas. As bactérias mais frequentemente presentes nas luvas internas foram: Staphylococcus, Enterococcus, Klebsiella spp, esporos aeróbicos, Micrococcus spp e E. coli. Tal achado aponta que diante de uma perfuração/rasgo, os índices de contaminação entre profissionais e pacientes e transferência dos microorganismos para a ferida operatória ou órgão cavidade são ampliados ${ }^{(7)}$.

Outras medidas, além da troca regular das luvas, são preconizadas na tentativa de manter a integridade das luvas, como o enluvamento duplo, sobretudo quando existe alto risco de perfuração da luva, como em cirurgias ortopédicas pela especificidade do instrumental, envolvimento com fragmentos ósseos, implantes de próteses ou no manuseio de pacientes portadores de doenças transmitidas por via sanguínea (hepatites B e C, HIV) e casos em que as consequências da contaminação podem ser catastróficas ${ }^{(4,11)}$. O uso de enluvamento duplo versus enluvamento único é capaz de reduzir a incidência de perfuração de 10 para $u^{(6)}$.

Contudo, alguns profissionais questionam a prática do enluvamento duplo, pois se sentem desconfortáveis com a sensação de perda da destreza e sensibilidade ${ }^{(45)}$. A escolha do tamanho adequado da luva torna a execução do procedimento cirúrgico mais confortável e segura. Assim, tem sido consenso entre os usuários que a utilização da luva maior no par externo é mais confortável do que sua utilização no par interno ${ }^{(6)}$. Nesse sentido, um trabalho descreveu a aceitação do enluvamento duplo por $88 \%$ dos participantes sem o questionamento de redução da sensibilidade tátil ${ }^{(46)}$. Já outro estudo mais recente com luvas mais espessas demonstrou redução dessa sensibilidade ${ }^{(47)}$.

Existe também o enluvamento duplo com indicador de perfuração que consiste na utilização de pares de luvas internos coloridos que na presença de fluidos sinaliza visivelmente onde a perfuração ocorreu, prática pouco difundida no Brasil. Esse sistema realça as perfurações e, consequentemente, aumenta a percepção do usuário, viabilizando a troca imediata da luva o que contribui para a redução da exposição ao material biológico pelo profissional ${ }^{(45,47-50)}$.

Outras práticas pouco difundidas também têm sido empregadas visando à manutenção da integridade das luvas cirúrgicas, como enluvamento triplo, utilização de luvas cirúrgicas mais espessas, forros de luvas e luvas de malha, demonstrando a incessante busca pela manutenção da barreira física proporcionada pelas luvas, essencial na prevenção da ISC ${ }^{(50)}$. 
As limitações desse estudo consistiram na diversidade de procedimentos e de formas de condução dos estudos analisados quanto à quantidade de luvas avaliadas, o tipo de enluvamento, teste de avaliação da perfuração de luva e intervalos de tempo extremamente variados encontrados nos trabalhos. Observou-se a necessidade de estudos mais robustos com variáveis e metodologia similares para viabilizar a elaboração de protocolos baseados em evidências na prática cirúrgica.

Nesse contexto, os enfermeiros possuem um papel relevante como gerenciadores do cuidado prestado livre de danos ao paciente, podendo ser um agente transformador dessa realidade nas salas cirúrgicas, contribuindo para a redução da contaminação do sítio cirúrgico e, consequentemente, a prevenção e controle de infecções do sítio cirúrgico, já que estão direta e indiretamente envolvido na assistência à esse público.

\section{CONCLUSÃO}

A falha na integridade das luvas cirúrgicas durante procedimentos operatórios é uma ocorrência comum, que viabiliza a exposição do paciente e do profissional de saúde a micro-organismos potencialmente causadores de infecção. Assim, uma prática recomendada para minimizar o desgaste do material da luva consiste na sua troca em procedimentos prolongados, uma vez que o aumento do tempo da cirurgia tem sido associado às perfurações.

Aspectos como qualidade da luva, tipo de procedimento cirúrgico, habilidade da equipe, tipo e condições do instrumental podem interferir na determinação do tempo, sendo sugerido a troca em menos de 120 minutos para cirurgias do aparelho digestivo, ginecológicas e torácicas, em menos de 90 minutos em cirurgias orais e maxilofaciais antes dos 60 minutos nas oftálmicas.

Contudo, são necessários mais estudos para fortalecer as evidências e embasar melhor as práticas, favorecendo a elaboração de protocolos com a definição do intervalo de tempo para a troca das luvas cirúrgicas relativos às diferentes especialidades cirúrgicas considerando suas especificidades, visando a segurança do paciente e dos profissionais envolvidos.

\section{REFERÊNCIAS}

1. Anderson DJ, Podgorny K, Berríos-Torres SI, Bratzler DW, Dellinger EP, Greene L, et al. Strategies to prevent surgical site infections in acute care hospitals: 2014 update. Infect Control Hosp Epidemiol. 2014; 35(6):605-27.

2. Agência Nacional de Vigilância Sanitária. Ministério da Saúde. Critérios diagnósticos de infecção relacionada à assistência à saúde / Ministério da Saúde, Agência Nacional de Vigilância Sanitária. - Brasília: Ministério da Saúde, 2013. $80 \mathrm{p}$.

3. Adams AB. Surgical hand antisepsis: where we have been and where we are today. Perioperative Nursing Clinics. 2010;5(4):443-8.

4. World Health Organization. WHO guidelines on hand hygiene in health care. Geneva: WHO; 2009. 270 p.

5. Widmer AF, Rotter M, Voss A, Nthumba P, Allegranzi B, Boyce J, et al. Surgical hand preparation: state-of-the-art. J Hosp Infect. 2010; 74(2):112-22.

6. Thomas-Copeland J. Do surgical personnel really need to double-glove? AORN J. 2009;89(2):322-8. 
7. Harnoß JC, Partecke LI, Heidecke CD, Hübner NO, Kramer A, Assadian O. Concentration of bacteria passing through puncture holes in surgical gloves. Am J Infect Control. 2010;38(2):154-8.

8. Misteli H, Weber W, Reck S, Rosenthal R, Zwahlen M, Fueglistaler P, et al. Surgical glove perforation and the risk of surgical site infection. Arch Surg 2009;144(6):553-8.

9. Alexander JW, Solomkin JS, Edwards MJ. Updated recommendations for control of surgical site infection. Ann Surg. 2011;253(6):1082-93.

10. Carter AH, Casper DS, Parvizi J, Austin MS. A prospective analysis of glove perforation in primary and revision total hip and total knee arthroplasty. J Arthroplasty. 2012; 27(7):1271-5.

11. National Institute for Health and Clinical Excellence. Surgical Site Infection: prevention and treatment of surgical site infection. 2008. 168p

12. Partecke IL, Goerdt AM, Langner I, Jaeger B, Assadian O, Heidecke CD, et al. Incidence of microperforation for surgical gloves depends on duration of wear. Infect Control Hosp Epidemiol. 2009;30(5):409-14.

13. Kaya I, Ugras A, Sungur I, Yilmaz M, Korkmaz M, Çetinus E. Glove perforation time and frequency in total hip arthroplasty procedures. Acta Orthop Traumatol Turc. 2012; 46(1):57-60.

14. Daeschlein G, Kramer A, Arnold A, Ladwig A, Seabrook GR, Edmiston CE. Evaluation of an innovative antimicrobial surgical glove technology to reduce the risk of microbial passage following intraoperative perforation. Am J Infect Control. 2011;39(2):98-103.

15. Oliveira AC, Gama CS. Evaluation of surgical glove integrity during surgery in a Brazilian teaching hospital. Am J Infect Control. 2014;42(10):1093-6.

16. Mendes KDS, Silveira RCCP, Galvão CM. Revisão integrativa: método de pesquisa para a incorporação de evidências na saúde e na enfermagem. Texto Contexto Enferm. 2008; 17(4):758-64.

17. Manjunath AP, Sheperd JH, Barton DPJ, Bridges JE, Ind TEJ. Glove perforations during open surgery for gynecological malignancies. BJOG. 2008;115:105-19.

18. Yinusa W, Li YH, Chow W, Ho WY, Leong JCY. Glove punctures in orthopaedic surgery. Int Orthop. 2003;28(1):36-9.

19. Malhotra M, Sharma JB, Wadhwa L, Arora R. Prospective study of glove perforation in obstetrical and gynecological operations: Are we safe enough? J Obstet Gynaecol Res. 2004;30(4):319-22.

20. Al-Habdan I, Sadat-Ali M. Glove perforation in pediatric orthopedic practice. J Pediatr Orthop. 2003;23(6):791-3.

21. Oliveira AC, Gama CS. Avaliação da adesão às medidas para a prevenção de infecções do sítio cirúrgico pela equipe cirúrgica. Rev Esc Enferm USP. 2015; 49(5):767-774

22. Al-Habdan I, Corea R, Sadat-Ali M. Double or single gloves: which is safer in pediatric orthopedic surgery. J Pediatr Orthop. 2006; 26(3):409-11.

23. Murta EFC, Silva CS, Júnior ORA. Frequency of glove perforation and the protective effect of double gloves in gynecological surgery. Arch Gynecol Obstet. 2003; 268(2):82-4.

24. Laine, T, Kaipia A, Santavirta J, Aarnio P. Glove perforations in open and laparoscopic abdominal surgery: the feasibility of double gloving. Scand J Surg. 2004; 93(1) 73-6.

25. Dhar D. Occult glove perforation during adult elective orthopaedic surgery. Macedonian Journal of Medical Sciences. 2011; 4(4):399-402.

26. Shek KM-Y, Chau JP-C. Surgical glove perforation among nurses in ophthalmic surgery: a case-control study. Int J Nurs Pract.2014; 20(2):179-86.

27. Kuroyanagi N, Nagao T, Sakuma H, Miyachi H, Ochiai S, Kimura Y, Fukano H, Shimozato K. Risk of surgical glove perforation in oral and maxillofacial surgery. Int. J. Oral Maxillofac. Surg. 2012; 41(8):1014-9.

28. Castro-Peraza ME, Garzón-Rodríguez E, Rodríguez-Pérez V, Sosa-Alvarez I, Gutierrez-Hernández J, Asiain-Ugarte C. Incidencia de la perforación de los guantes en cirurgía y efecto protector del doble guante. Enferm Clin.

2010;20(2):73-9.

29. Kojima Y, Ohashi M. Unnoticed glove perforation during thoracoscopic and open thoracic surgery. Ann Thorac Surg. 2005;80(3):1078-80.

30. Guo YP, Wong PM, Li Y, Or PPL. Is double-gloving really protective? A comparison between the glove perforation rate among perioperative nurses with single and double gloves during surgery. Am J Surg. 2012;204(2):210-5.

31. Hübner NO, Goerdt AM, Stanislawski N, Assadian O, Heidecke CD, Kramer A, et al. Bacterial migration through punctured surgical gloves under real surgical conditions. BMC Infect Dis. 2010;10:192.

32. Korniewicz D, Garzon L, Seltzer J, Feinleib M. Failure rates in nonlatex surgical gloves. Am J Infect Control. 2004;32(5):268-73. 
33. Comité Européen de Normalisation. EN 455-1. Medical glove for single use. Berlin; 2000, 7 p.

34. American Society for Testing and Materials. ASTM D3577-06e1 standard specification for rubber surgical gloves. ASTM International. 2006 http://www.astm.org/Standards/D3577.htm. Acessado em 15 de agosto de 2014. 35. Resolução da Diretoria Colegiada 55 de 04 de novembro de 2011 (BR). Estabelece os requisitos mínimos de identidade e qualidade para as luvas cirúrgicas e luvas para procedimentos não cirúrgicos de borracha natural, de borracha sintética, de mistura de borrachas natural e sintética e de policloreto de vinila, sob regime de vigilância sanitária. Diário Oficial da União. 04 nov 2011.

36. Becerra V, Fernández AL, Adrio B, Rubio J, Sierra J, García J, et al. Perforación de los guantes e infección de la herida de esternotomía en cirugía cardíaca con circulación extracorpórea. Cir Cardiov. 2015; 22(1):25-30.

37. Murta EFC, Silva CS, Ferreira NAFD. Perfuração de luvas durante cirurgias ginecológicas. Rev Bras Ginecol Obstet. 2000;22(4):225-8.

38. Oberg C, Schwartz JP, Zander Grande F, Ruan JD, Santos EB. Passagem de microrganismos através de luvas de procedimento e de luvas cirúrgicas antes de sua utilização. Rev Odontol UNESP. 2007;36(2):127-30.

39. Beldame J, Lagrave B, Lievain L, Lefebvre B, Frebourg N, Dujardin F. Surgical glove bacterial contamination and perforation during total hip arthroplasty implantation: When gloves should be changed. Orthop Traumatol Surg Res. 2012;98(4):432-40.

40. Dawson-Bowling S, Smith J, Butt D, Cottam H, Umasankar S, Armitage A. Should outer surgical gloves be changed intraoperatively before orthopaedic prosthesis implantation? J Hosp Infect. 2011; 78(2):152-9.

41. Al-Maiyah M, Bajwa A, Finn P, Mackenney P, Hill D, Port A, et al. Glove perforation and contamination in primary total hip arthroplasty. J Bone Joint Surg Br. 2005;87-B(4):556-9.

42. Demircay E, Unay K, Bilgili MG, Alataca G. Glove perforation in hip and knee arthroplasty. J Orthop Sci.

2010;15(6):790-4.

43. Harnoss JC, Kramer A, Heidecke CD, Assadian O. What is the appropriate time-interval for changing gloves during surgical procedures. Zentralbl Chir. 2010 Feb;135(1):25-7.

44. Castro-Peraza ME, Garzón-Rodríguez E, Rodríguez-Pérez V, Sosa-Alvarez I, Gutierrez-Hernández J, Asiain-Ugarte C. Incidencia de la perforación de los guantes en cirurgía y efecto protector del doble guante. Enferm Clin.

2010;20(2):73-9.

45. Laine T, Aarnio P. How often does glove perforation occur in surgery? Comparison between single gloves and a double-gloving system. Am J Surg. 2001;181(6):564-6.

46. Quebbeman EJ, Telford GL, Wadsworth K, Hubbard S, Goodman H, Gottlieb MS. Double gloving: protecting surgeons from blood contamination in the operating room. Arch Surg. 1992;127(2):213-7.

47. Han CD, Kim J, Moon SH, Lee BH, Kwon HM, Park KK. A randomized prospective study of glove perforation in orthopaedic surgery: is a thick glove more effective? J Arthroplasty. 2013;28(10):1878-81.

48. Korniewicz D, El-Masri M. Exploring the benefits of double gloving during surgery. AORN J. 2012;95(3):328-36. 49. Phillips S. The comparison of double gloving to single gloving in the theatre environment. J Perioper Pract. 2011;21(1):10-5.

50. Tanner J. Choosing the right surgical glove: an overview and update. Br J Nurs. 2008;17(12):740-4. 